\title{
Striatal Indirect Pathway Contributes to Selection Accuracy of Learned Motor Actions
}

\author{
Kayo Nishizawa, ${ }^{1}$ Ryoji Fukabori, ${ }^{1}$ Kana Okada, ${ }^{1,2}$ Nobuyuki Kai, ${ }^{1}$ Motokazu Uchigashima, ${ }^{3}$ Masahiko Watanabe, ${ }^{3}$ \\ Akira Shiota, ${ }^{4}$ Masatsugu Ueda, ${ }^{4}$ Yuji Tsutsui, ${ }^{5}$ and Kazuto Kobayashi ${ }^{1,2}$ \\ ${ }^{1}$ Department of Molecular Genetics, Institute of Biomedical Sciences, Fukushima Medical University School of Medicine, Fukushima 960-1295, Japan, ${ }^{2}$ Core \\ Research for Evolutional Science and Technology, Japan Science and Technology Agency, Kawaguchi 332-0012, Japan, ${ }^{3}$ Department of Anatomy, Hokkaido \\ University School of Medicine, Sapporo 060-8638, Japan, ${ }^{4}$ Utsunomiya Branch, PhoenixBio, Utsunomiya 321-0973, Japan, and ${ }^{5}$ Faculty of Symbiotic \\ Systems Science, Fukushima University, Fukushima 960-1296, Japan
}

The dorsal striatum, which contains the dorsolateral striatum (DLS) and dorsomedial striatum (DMS), integrates the acquisition and implementation of instrumental learning in cooperation with the nucleus accumbens (NAc). The dorsal striatum regulates the basal ganglia circuitry through direct and indirect pathways. The mechanism by which these pathways mediate the learning processes of instrumental actions remains unclear. We investigated how the striatal indirect (striatopallidal) pathway arising from the DLS contributes to the performance of conditional discrimination. Immunotoxin targeting of the striatal neuronal type containing dopamine $\mathrm{D}_{2}$ receptor in the DLS of transgenic rats resulted in selective, efficient elimination of the striatopallidal pathway. This elimination impaired the accuracy of response selection in a two-choice reaction time task dependent on different auditory stimuli. The impaired response selection was elicited early in the test sessions and was gradually restored as the sessions continued. The restoration from the deficits in auditory discrimination was prevented by excitotoxic lesion of the NAc but not by that of the DMS. In addition, lesion of the DLS mimicked the behavioral consequence of the striatopallidal removal at the early stage of test sessions of discriminative performance. Our results demonstrate that the DLS-derived striatopallidal pathway plays an essential role in the execution of conditional discrimination, showing its contribution to the control of selection accuracy of learned motor responses. The results also suggest the presence of a mechanism that compensates for the learning deficits during the repetitive sessions, at least partly, demanding accumbal function.

\section{Introduction}

Accumulating evidence indicates important roles for the dorsal striatum, nucleus accumbens (NAc), and their linked structures in the acquisition and implementation of instrumental conditioning (Cardinal et al., 2002a; Packard and Knowlton, 2002; Everitt and Robbins, 2005; Balleine et al., 2009). The dorsal striatum contains the dorsolateral striatum (DLS) and dorsomedial striatum (DMS) characterized by dense innervations from the sensorimotor and prefrontal cortices, respectively (McGeorge and Faull, 1989; Gabbott et al., 2005). The DLS and DMS possess dissociable roles for goal-directed and habitual learning processes (Yin et al., 2004, 2009). In particular, excitotoxic lesion of these

Received April 23, 2012; revised July 4, 2012; accepted July 27, 2012.

Author contributions: K.N. and K.K. designed research; K.N., R.F., K.O., N.K., M. Uchigashima, M.W., A.S., and M. Ueda performed research; Y.T. contributed unpublished reagents/analytic tools; K.N., R.F., K.O., N.K., M. Uchigashima, M.W., A.S., M. Ueda, Y.T., and K.K. analyzed data; K.N. and K.K. wrote the paper.

This work was supported by Grants-in-Aid for Scientific Research (B) and Scientific Research on Innovative Areas (Comprehensive Brain Science Network) from the Ministry of Education, Science, Sports, and Culture of Japan; and Core Research for Evolutional Science and Technology of Japan Science and Technology Agency. We thank Dr. I. Pastan for providing anti-Tac(Fv)-PE38. We are grateful to M. Kikuchi, N. Sato, K. Sato, and T. Kobayashi for their technical support in the animal experiments.

The authors declare no competing financial interests.

Correspondence should be addressed to Dr. Kazuto Kobayashi, Department of Molecular Genetics, Institute of Biomedical Sciences, Fukushima Medical University School of Medicine, Fukushima 960-1295, Japan. E-mail: kazuto@fmu.ac.jp.

DOI:10.1523/JNEUROSCI.1969-12.2012

Copyright $\odot 2012$ the authors $\quad 0270-6474 / 12 / 3213421-12 \$ 15.00 / 0$ subregions impairs selection and initiation of motor responses in sensory discrimination tasks (Brown and Robbins, 1989; Featherstone and McDonald, 2004, 2005). The NAc receives inputs from various brain regions including the prefrontal cortex, hippocampus, and amygdala (Groenewegen et al., 1999) and acts to mediate instrumental responding (Reading et al., 1991; Kelley et al., 1997). The functional connectivity between the dorsal striatum and NAc through the ventral midbrain is involved in the development and performance of habitual learning (Belin and Everitt, 2008).

The dorsal striatum projects to the output nuclei in basal ganglia circuit, including the substantia nigra pars reticulata $(\mathrm{SNr})$ and entopeduncular nucleus, which form the feedback loop to the cortical areas (Alexander and Crutcher, 1990; Parent and Hazrati, 1995). Striatal projections consist of two subpopulations of GABAergic medium spiny neurons that constitute the direct and indirect pathways. The striatonigral neurons in the direct pathway provide monosynaptic inhibition to the output nuclei, whereas the striatopallidal neurons in the indirect pathway inhibit the globus pallidus (GP). The GP neurons connect to the output nuclei monosynaptically or via the subthalamic nucleus (STN). These two pathways have been considered to regulate motor functions through their opposing influences on the output activity. A recent optogenetic study shows that excitation of striatonigral and striatopallidal neurons acts bidirectionally on locomotion and its initiation (Kravitz et al., 2010). Silencing of the 
A

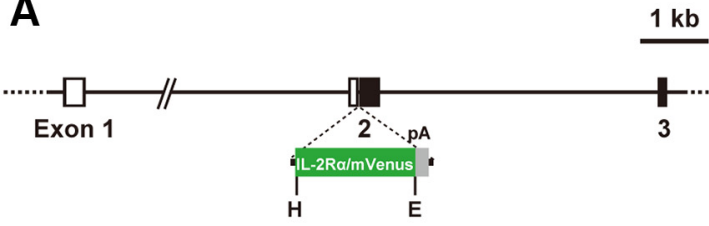

B

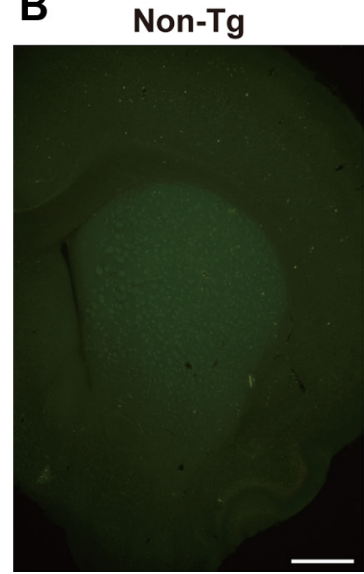

$\mathrm{Tg}$

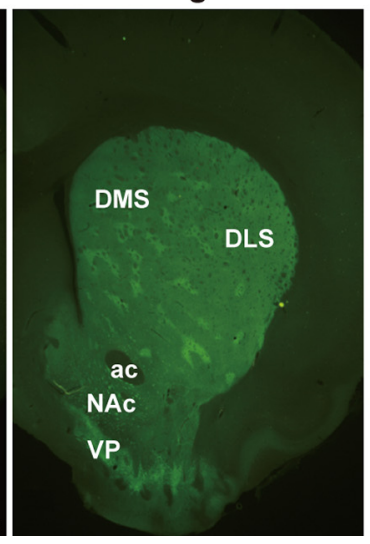

C
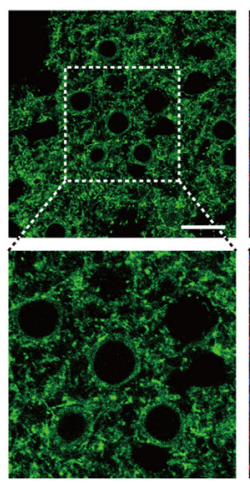

D

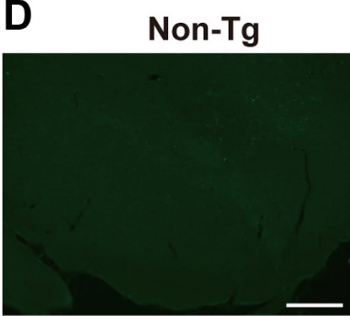

$D_{1} R / D_{2} R$
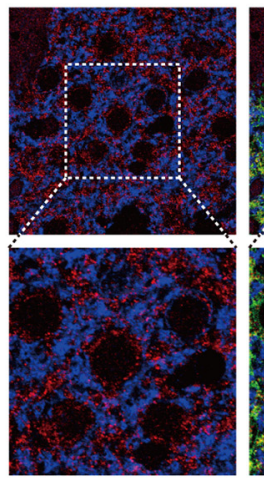

$\mathrm{Tg}$
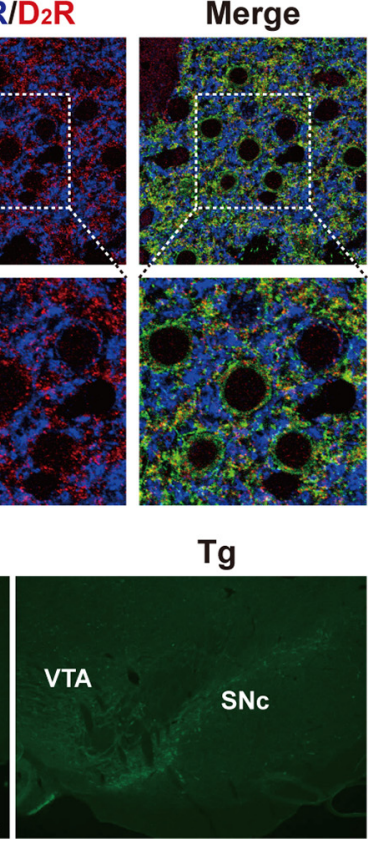

Figure 1. Generation of Tg rats expressing IT receptor under the control of the Drd2 gene promoter. $A$, Structure of the transgene construct. The gene cassette encoding IL-2R $\alpha / \mathrm{mVenus} \mathrm{followed}$ by the SV40 early gene polyadenylation signal (pA) was introduced into the place of the initiation codon in exon 2 of the rat Drd2 gene. Exons $1-3$ of the rat Drd2 gene are shown. Open and closed boxes indicate the $5^{\prime}$-noncoding and coding regions, respectively. E, EcoRl; H, HindIII. B, Detection of endogenous fluorescence in sections through the striatum prepared from Tg and non-Tg rats. Transgene expression is observed in the DLS, DMS, NAC, and ventral pallidum (VP) in the Tg rats. ac, anterior commissure. C, Triple immunofluorescence histochemistry for mVenus, $D_{1} R$, and $D_{2} R$ with sections through the DLS. mVenus-, $D_{1} R$-, and $D_{2} R$-positive signals are shown in green, blue, and red, respectively. In a merged image, green signals overlap with red signals, and thus emit yellow signals. Lower images are magnified views of squares in upper images. $\boldsymbol{D}$, Immunofluorescence histochemistry for mVenus with sections through the ventral midbrain. Transgene expression is observed in the SNc and VTA in the Tg rats. Scale bars: $\boldsymbol{B}, 1 \mathrm{~mm} ; \boldsymbol{C}, 20 \mu \mathrm{m} ; \boldsymbol{D}, 400 \mu \mathrm{m}$.

activity of these neurons alters differentially behavioral sensitization to psychostimulant treatment (Ferguson et al., 2011). In addition, targeting of the striatonigral pathway reveals that this pathway modulates response time in sensory discrimination ( $\mathrm{Fu}-$ kabori et al., 2012). However, less is known how the striatopallidal pathway controls the mechanism underlying learning processes of instrumental actions.

We addressed the behavioral role of striatal indirect pathway arising from the DLS in the performance of auditory conditional discrimination. We induced selective elimination of striatal neuronal type containing dopamine $\mathrm{D}_{2}$ receptor $\left(\mathrm{D}_{2} \mathrm{R}\right)$ in transgenic ( Tg) rats by immunotoxin (IT)-mediated cell targeting (Kobayashi et al., 1995). Elimination of the striatopallidal pathway disturbed the accuracy of response selection at the early phase in execution of conditional discrimination, and the disturbed performance was recovered during the continuing sessions. The recovery of learning deficits was prevented by excitotoxic lesion of the NAc but not by that of the DMS. Our data show that DLS striatopallidal pathway is engaged in the process controlling selection accuracy of learned motor responses, suggesting that the learning deficits can be compensated, at least partly, through accumbal function.

\section{Materials and Methods}

Generation of $\mathrm{Tg}$ rats. A rat bacterial artificial chromosome (BAC) clone encoding the $\mathrm{D}_{2} \mathrm{R}$ gene ( $\left.\mathrm{Drd} 2, \mathrm{CH} 230-11 \mathrm{~B} 15\right)$ was selected from the CHORI-230 Female Brown Norway rat BAC Library (BACPAC Resources Center, Children's Hospital Oakland Research Institute) by search of the rat BAC ends database at the National Center for Biotechnology Information. The gene cassette encoding human interleukin-2 receptor $\alpha$-subunit (IL-2R $\alpha$ ) fused to a variant of enhanced yellow fluorescent protein or mVenus (Hatsuzawa et al., 2006) followed by the SV40 early gene polyadenylation signal was introduced into the place of the initiation methionine codon in exon 2 of the rat $\operatorname{Drd} 2$ gene by use of a Red/ET quick and easy BAC modification kit (Gene Bridges) (see Fig. $1 A)$. The transgene construct $(\sim 250 \mathrm{~kb})$ was linearized by PI-SceI digestion and purified by pulse field gel electrophoresis. The construct was microinjected into fertilized Long-Evans rat eggs, which were then implanted into pseudopregnant females. Tg rats were identified by Southern blot hybridization or PCR with genomic DNA prepared from tail clips. Animal care and handling procedures were conducted in accordance with the guidelines established by the Experimental Animal Center of Fukushima Medical University.

Intracranial surgery. Rats were anesthetized with sodium pentobarbital ( $50 \mathrm{mg} / \mathrm{kg}$, i.p.), and subjected to unilateral or bilateral intrastriatal injection as described previously (Kobayashi et al., 2012). Anti-Tac (Fv)-PE38, which is a recombinant IT composed of anti-IL-2R $\alpha$ monoclonal antibody variable region fused to a bacterial exotoxin fragment (Kreitman et al., 1994), was diluted to a final concentration of $10 \mu \mathrm{g} / \mathrm{ml}$ in PBS containing $0.1 \%$ rat serum albumin. The IT solution or PBS $(0.8 \mu \mathrm{l} / \mathrm{site})$ was injected into 12 sites of the DLS through a glass micropipette, which was stereotaxically introduced by using the coordinates according to an atlas of the rat brain (Paxinos and Watson, 2005). The anteroposterior, mediolateral, and dorsoventral coordinates (millimeters) from bregma and dura were 1.2/2.65/2.8 (site 1), 1.2/2.65/3.45 (site 2), 1.2/3.4/3.05 (site 3), 1.2/3.4/3.7 (site 4), 0.4/3.15/2.95 (site 5), 0.4/3.15/ 3.5 (site 6), 0.4/4.3/3.35 (site 7), 0.4/4.3/3.9 (site 8), $-0.4 / 3.65 / 3$ (site 9), $-0.4 / 3.65 / 3.55$ (site 10 ), $-0.4 / 4.3 / 3.45$ (site 11 ), and $-0.4 / 4.3 / 4.05$ (site 12) (see Fig. 2A). Injection was performed at a constant flow rate of 0.4 $\mu \mathrm{l} / \mathrm{min}$ with a microinfusion pump.

For anterograde axonal labeling, a solution containing 5\% biotinylated dextran amine (BDA; molecular weight 10,000, Life Technologies) was injected into six sites of the DLS $(0.1 \mu \mathrm{l} / \mathrm{site})$ by using the anteroposterior, mediolateral, and dorsoventral coordinates (millimeters) from bregma and dura: 1.2/2.65/3.45 (site 1), 1.2/3.4/3.7 (site 2), 0.4/3.15/3.5 (site 3), 0.4/4.3/3.9 (site 4), $-0.4 / 3.65 / 3.55$ (site 5 ), and $-0.4 / 4.3 / 4.05$ 
A

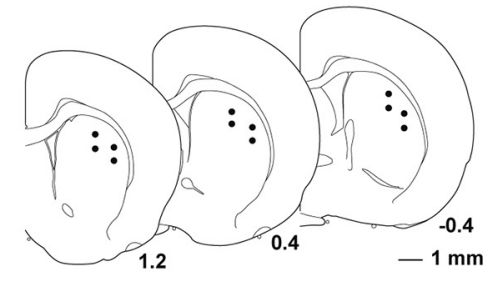

B
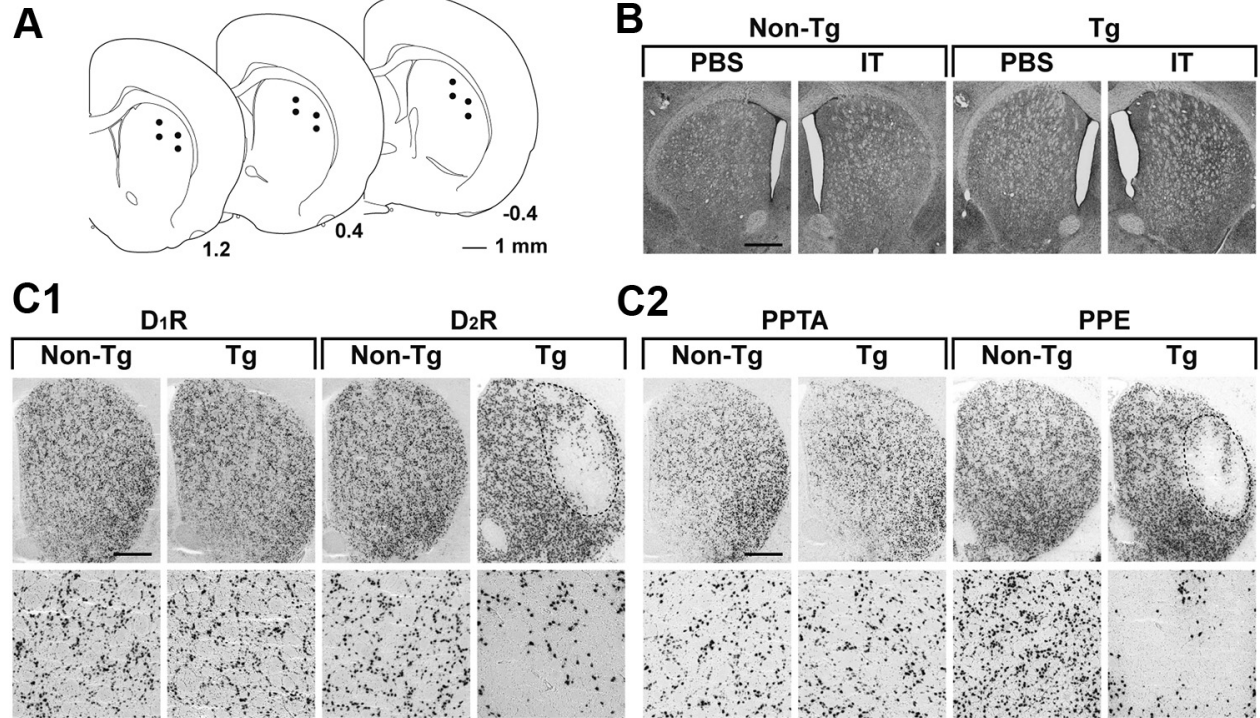

C2
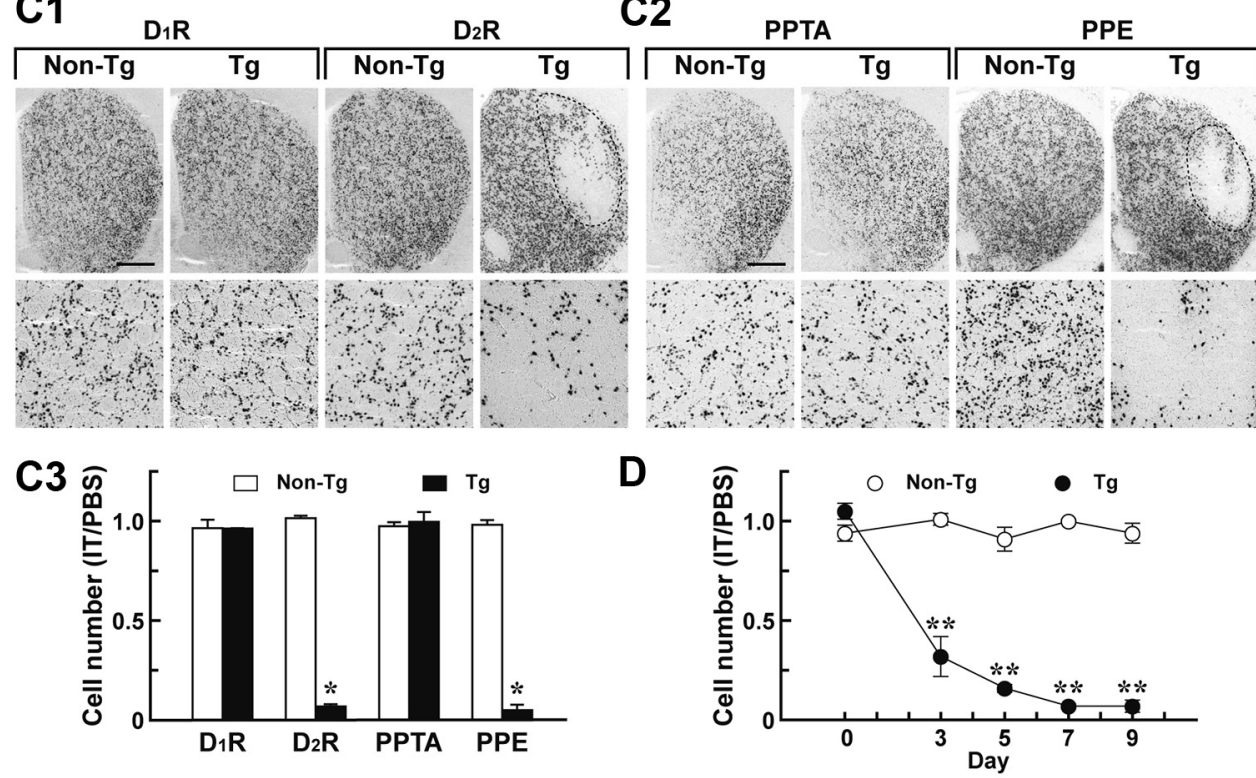

E

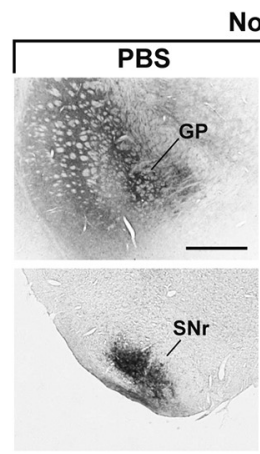

Non-Tg

$\mathrm{Tg}$

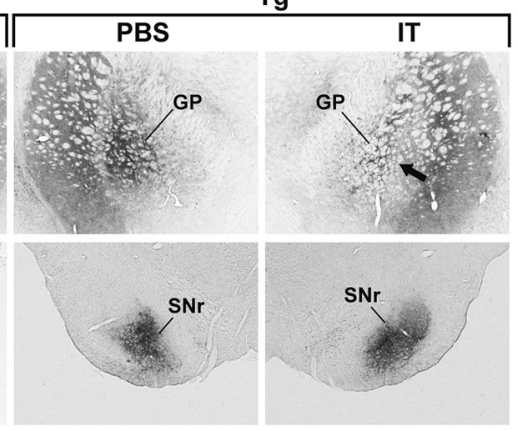

Figure 2. Selective targeting of the striatopallidal pathway arising from the DLS. Rats were unilaterally injected with IT or PBS into their DLS and processed for histological analysis. A, Schematic illustration of coordinates for the injection. The anteroposterior coordinates (millimeters) from bregma are shown. $\boldsymbol{B}$, (resyl violet staining of sections through the striatum prepared from the rats $7 \mathrm{~d}$ after the injection. C, In situ hybridization analysis of medium spiny neurons. Sections were hybridized with labeled riboprobe for a rat $\mathrm{D}_{1} \mathrm{R}$ or $\mathrm{D}_{2} \mathrm{R}$ sequence (C1) or for a rat PPTA or PPE sequence (C2). Top, light microscopic images of the dorsal striatum on the IT-injected side. Bottom, magnified views of the DLS region. Cell counts of in situ hybridization images are also shown (C3). The ratio of cell number on the IT-injected side relative to that on the PBS-injected side was calculated. $n=4$ for each group. ${ }^{*} p<0.001$, significant differences from the non-Tg rats (Student's $t$ test). $\boldsymbol{D}$, Time course of neuron elimination. Striatal sections were prepared from the rats on different days after the injection and stained by in situ hybridization with the $D_{2} R$ probe. The ratio of cell number on the IT-injected side relative to that on the PBS-injected side is plotted. $n=4$ for each group. ${ }^{* *} p<0.01$, compared with the non-Tg group, LSD test. $\boldsymbol{E}$, Anterograde axonal tracing. Rats were injected bilaterally with BDA solution into their DLS and then used for unilateral treatment with IT or PBS. Sections through the GP and SNr were stained for BDA signals. The arrow indicates the reduced density of striatopallidal nerve terminals on the IT-injected side of the Tg rats. Scale bars: $A, 1 \mathrm{~mm} ; \boldsymbol{B}, C, E, 500 \mu \mathrm{m}$.

(site 6). Injection was performed at a constant velocity of $0.1 \mu \mathrm{l} / \mathrm{min}$ with the microinfusion pump.

For excitotoxic lesion, a solution containing $8 \mathrm{mg} / \mathrm{ml}$ ibotenic acid (IBO; Wako Pure Chemical) was injected into two sites of the NAc or three sites of the DMS/DLS ( $0.25 \mu \mathrm{l} / \mathrm{site})$. The anteroposterior, mediolateral, and dorsoventral coordinates (millimeters) from bregma and dura were 2.2/1.4/6 (site 1) and 1.6/1.4/6.5 (site 2) for the intraaccumbal injection, $1.8 / 1.8 / 3.2$ (site 1), 1.1/2.0/3.1 (site 2), and $0.3 /$ 2.3/3.2 (site 3) for the intra-DMS injection, and 1.6/3.2/3.7 (site 1), $0.8 / 3.9 / 4$ (site 2 ), and $-0.5 / 4.5 / 3.8$ (site 3 ) for the intra-DLS injection. Injection was performed at a constant velocity of $0.1 \mu \mathrm{l} / \mathrm{min}$ with the microinfusion pump.
Histology. Rats were anesthetized with sodium pentobarbital and perfused transcardially with PBS followed by $4 \%$ paraformaldehyde in $0.1 \mathrm{M}$ phosphate buffer, $\mathrm{pH}$ 7.4. Fixed brains were cut into sections $(30 \mu \mathrm{m}$ thick) through a coronal plane with a cryostat. For immunohistochemistry, the sections were incubated with primary antibodies for IL-2R $\alpha$ (goat, 1:10,000; Sigma-Aldrich), green fluorescent protein (GFP; rabbit, 1:2000, Life Technologies), choline acetyltransferase (rabbit, 1:200; Millipore), parvalbumin (rabbit, 1:1000; Sigma-Aldrich), somatostatin (rabbit, 1:1000; Dako), calretinin (rabbit, 1:1000; Millipore), tyrosine hydroxylase (TH; mouse, 1:300; Millipore), vesicular glutamate transporter 1 (rabbit, 1:1000; Synaptic Systems), vesicular glutamate transporter 2 (rabbit, 1:1000; Synaptic Systems) or NeuN (mouse, 1:400; 
A1

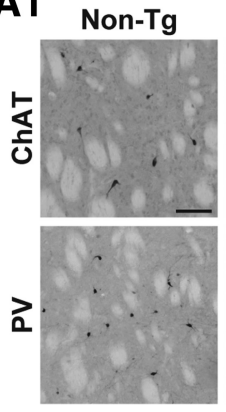

A2

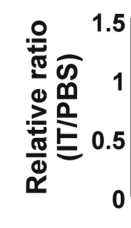

$\operatorname{Tg}$

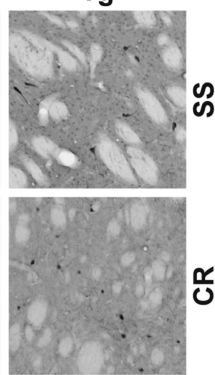

ชิ

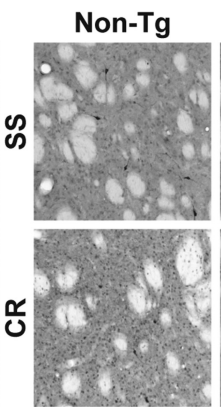

(1.20)

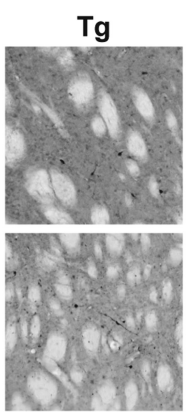

B1

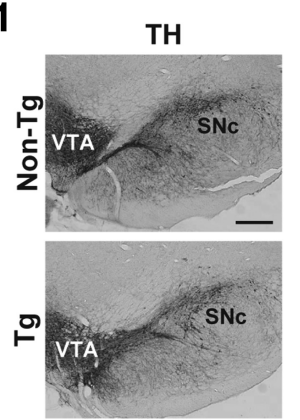

B2

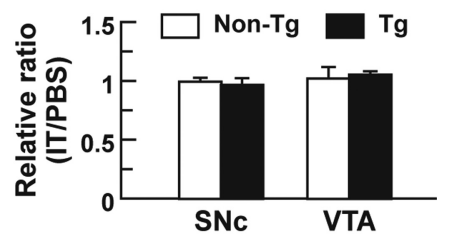

C
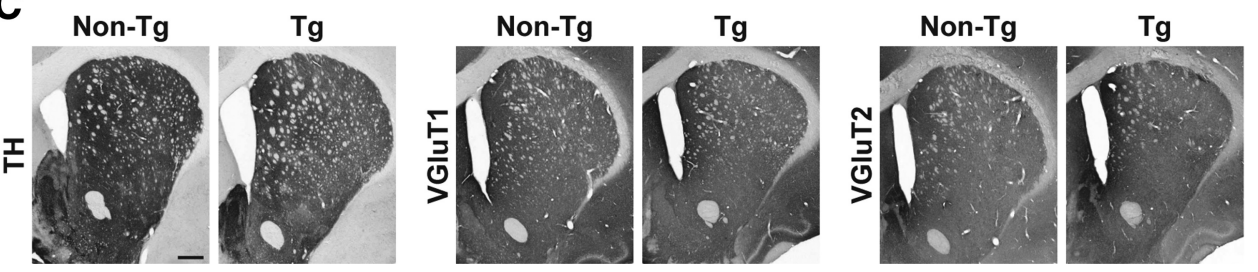

Figure 3. Impact of IT injection on striatal interneuronal types, midbrain dopaminergic neurons, and synaptic terminals in the DLS. A, Localization of striatal interneuronal types. Sections through the dorsal striatum were stained immunohistochemically for specific markers of the interneurons, including choline acetyltransferase (ChAT) for cholinergic interneurons and parvalbumin (PV), somatostatin (SS), and calretinin (CR) for GABAergic interneurons. Light microscopic images of the DLS on the IT-injected side are shown (A1). Cell number ratios for the immunohistochemical images on the IT-injected side relative to the PBS-injected side were calculated (A2). $n=4$ for each group. $\boldsymbol{B}$, Morphology of midbrain dopaminergic neurons. Sections through the ventral midbrain including the SNc and VTA were stained immunohistochemically for TH. Light microscopic images on the IT-injected side are shown (B1). Cell number ratios for the immunohistochemical images on the IT-injected side relative to the PBS-injected side were calculated (B2). $n=4$ for each group. C, Distribution of dopaminergic and glutamatergic nerve fibers. Striatal sections were stained immunohistochemically for TH and vesicular glutamate transporters $1 / 2$ (VGluT1/2) to visualize dopaminergic and glutamatergic fibers, respectively. Light microscopic images on the IT-injected side are presented. Scale bars: $\boldsymbol{A}, 100 \mu \mathrm{m} ; \boldsymbol{B}, 400 \mu \mathrm{m} ; \boldsymbol{C}, 1 \mathrm{~mm}$.

Millipore Bioscience Research Reagents), and then with biotinylated secondary antibodies (anti-rabbit IgG, 1:1000 and anti-mouse IgG, 1:500; Jackson ImmunoResearch Laboratories and anti-rat IgG 1:250, MP Biomedicals). The immunoreactive signals were visualized by using a Vectastain Elite $\mathrm{ABC}$ kit with 3,3' -diaminobenzidine tetrahydrochloride $/ \mathrm{H}_{2} \mathrm{O}_{2}$ as the chromogen (Vector Laboratories). For triple immunofluorescence histochemistry, sections were incubated with anti-GFP antibody (goat, $1 \mu \mathrm{g} / \mathrm{ml}$; Frontier Science), anti-dopamine $D_{1}$ receptor $\left(D_{1} R\right)$ antibody (guinea pig, $1 \mu \mathrm{g} / \mathrm{ml}$ ) (Narushima et al., 2006), and anti- $\mathrm{D}_{2} \mathrm{R}$ antibody (rabbit, $1 \mu \mathrm{g} / \mathrm{ml}$ ) (Narushima et al., 2006), and then with species-specific secondary antibodies conjugated to Alexa 488 (Invitrogen), Cy3, or Cy5 (Jackson ImmunoResearch). Fluorescent images were obtained with a confocal laser-scanning microscope equipped with proper filter cube specifications. For axonal labeling, the signals containing $\mathrm{BDA}$ were visualized with the Vectastain Elite $\mathrm{ABC}$ kit using 3,3'-diaminobenzidine tetrahydrochloride $/ \mathrm{H}_{2} \mathrm{O}_{2}$ and nickel ammonium sulfate.

For in situ hybridization, fresh-frozen sections (10 $\mu \mathrm{m}$ thick) through the striatum were fixed in a solution of $4 \%$ paraformaldehyde in $0.1 \mathrm{M}$ phosphate buffer and treated with $0.1 \mathrm{M}$ triethanolamine, $\mathrm{pH}$ 8.0 , containing $0.25 \%$ acetic anhydride. The sections were then hybridized with antisense RNA probes labeled by using in vitro transcription with digoxigenin-11-UTP (Roche). The signals were visualized with a nonradioactive detection system using antidigoxigenin $\mathrm{Fab}$ fragment conjugated to alkaline phosphatase (Roche). The number of stained cells in a region of interest $(0.75 \times$ $0.75 \mathrm{~mm}$ ) in the DLS was counted, and four sections from a single animal were selected for cell counts.

Behavioral analysis. Age-matched male rat littermates (12-15 weeks old) were used for the behavioral experiments. Rats were handled for 3-5 $\mathrm{d}$ before the experiments, and the food feeding was controlled to maintain $85 \%$ of ad libitum weight for operant conditioning tasks. The auditory two-choice reaction time and progressive ratio tests were conducted in an operant chamber $(30.5 \times 24.1 \times 29.2 \mathrm{~cm})$ equipped with a pellet receptacle in the center of a front panel (ENV-007CT; MED Associates), two retractable levers mounted at either side of the receptacle, and a speaker linked to a programmable tone generator (ENV-230; MED Associates). The chamber was enclosed in a sound-attenuating box and illuminated with a house light during the trials. Rats were shaped to press the lever to obtain the delivery of a $45 \mathrm{mg}$ food pellet (Bio-Serv).

For the auditory two-choice reaction time task, a training schedule was composed of two continuous phases. In the first phase, the rats were required to press one of the two levers (right or left) randomly presented for food pellet delivery. In the second phase, the rats were reinforced to press one of these two levers dependent on different auditory stimuli (tone $\mathrm{A}$ of $10 \mathrm{kHz}, 75 \mathrm{~dB}$ for the right lever; and tone $\mathrm{B}$ of $2 \mathrm{kHz}, 75 \mathrm{~dB}$ for the left one) within a $5 \mathrm{~s}$ test period after the onset of lever presentation. The tone stimulation proceeded for $0.5 \mathrm{~s}$ before the lever presentation and continued until the emission of lever press responses. The intertrial interval was $20 \mathrm{~s}$ throughout these two phases. Each session was ended when 40 rewards were earned or when $30 \mathrm{~min}$ had elapsed. The rats, when they had earned 100 rewards in the first phase, advanced to the second phase. When the average of the correct response ratio in 3 consecutive $\mathrm{d}$ attained $>80 \%$ in the second phase, they received the intracranial injection. After a $7 \mathrm{~d}$ recovery from the surgery, the animals were tested by the same task program as used in the second phase.

For the open field test, rats were placed in the center of an open field (width $\times$ depth $\times$ height, $70 \times 70 \times 40 \mathrm{~cm}$ ) equipped with a digital video camera to monitor the animal behavior. Spontaneous locomotion was recorded during a $60 \mathrm{~min}$ test period. Total distance and average velocity 

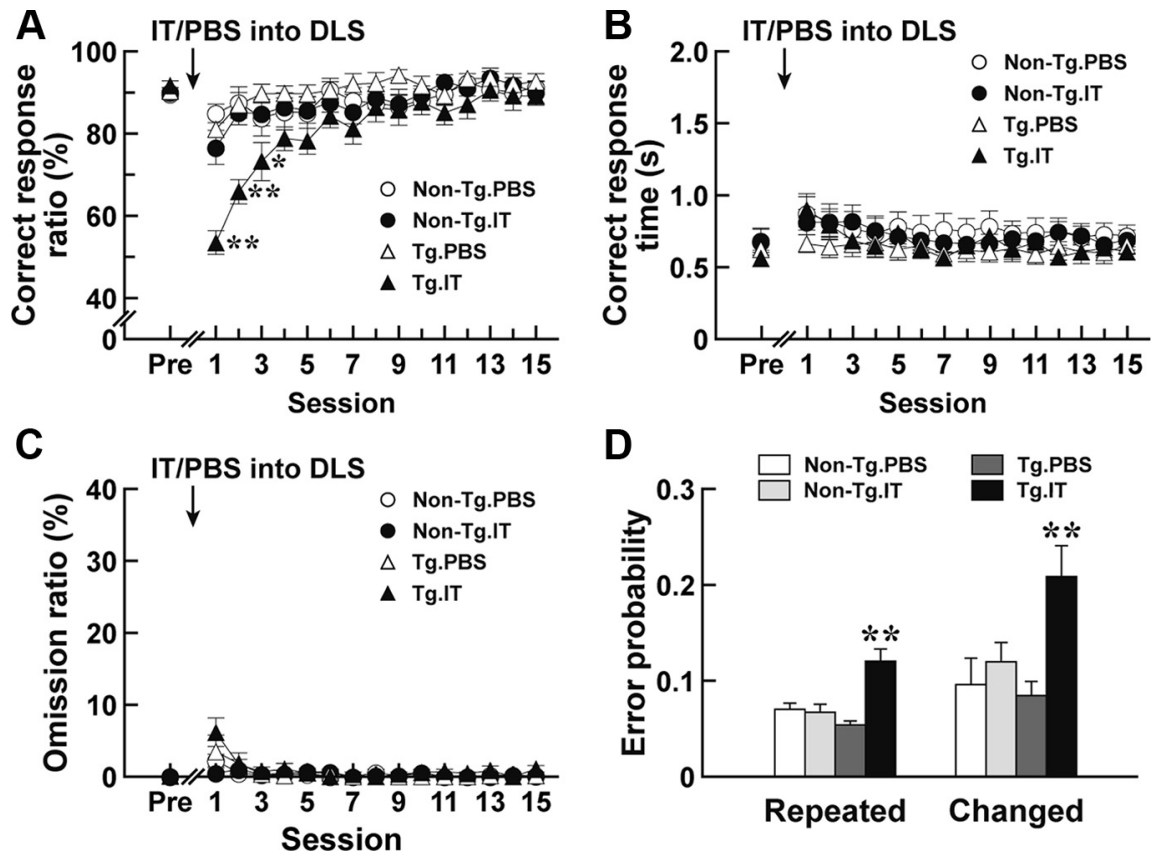

Figure 4. Performance of auditory discrimination in rats lacking the striatopallidal pathway originating from the DLS. Rats ( $n=$ 12-16 for each group) were trained for the auditory two-choice reaction time task. After the rats had achieved the $80 \%$ criterion, they were given a bilateral injection of IT or PBS into the DLS, and then tested for the task performance. The correct response ratio $(\boldsymbol{A})$, correct response time $(\boldsymbol{B})$, and omission ratio $(\boldsymbol{C})$ in each session are plotted. The values at the pretreatment phase (Pre) are the averages at $3 \mathrm{~d}$ before the injection. ${ }^{* *} p<0.01$, compared with each of the non- $\mathrm{Tg} / \mathrm{PBS}$, non- $\mathrm{Tg} / \mathrm{IT}$, and $\mathrm{Tg} / \mathrm{PBS}$ groups; ${ }^{*} p<$ 0.05 , compared with the Tg/PBS group, LSD test. Error probability for the stimulus repeated or changed is also given $\boldsymbol{D}$. The probability was calculated on the basis of the two stimulation patterns. ${ }^{* *} p<0.01$, compared with each of the other three rat groups, LSD test.
$1 A$ ), because $\mathrm{D}_{2} \mathrm{R}$ is localized in the majority of striatopallidal neurons (Gerfen et al., 1990, 1995; Hersch et al., 1995; Yung et al., 1995). Using the microinjection technique, we generated eight independent $\mathrm{Tg}$ rat founders. One Tg strain, termed $\mathrm{Drd2}$ $I L-2 R \alpha / m$ Venus -76 , expressed the highest level of fluorescence in the DLS, DMS, NAc, and ventral pallidum (Fig. $1 B$ ). The expression pattern of IL-2R $\alpha /$ mVenus in the striatum was analyzed by triple immunofluorescence histochemistry for $\mathrm{D}_{1} \mathrm{R}$, $\mathrm{D}_{2} \mathrm{R}$, and mVenus. The mVenus-positive signals appeared to be localized in the majority of $\mathrm{D}_{2} \mathrm{R}$-positive neurons $(\sim 93 \%)$ but not in $\mathrm{D}_{1}$ R-positive neurons (Fig. 1C). In addition, $\mathrm{D}_{2} \mathrm{R}$ is reported to be expressed in dopaminergic neurons in the ventral midbrain (Levey et al., 1993; Yung et al., 1995). Sections through the ventral midbrain were stained by immunofluorescence histochemistry for mVenus. The transgene expression was detected in the substantia nigra pars compacta $(\mathrm{SNc})$ and ventral tegmental area (VTA) in the Tg rats (Fig. 1D). These data suggest neuronal typespecific expression of the transgene driven by the rat $D r d 2$ gene promoter. In this study, we used the Drd2-IL-2R $\alpha / m$ Venus-76 Tg and non-Tg littermates for the experiments described below. of ambulation for every 10 min session were measured by using a video tracking software (Viewer2; Biobserve).

For the progressive ratio test, rats were initially trained by using a continuous reinforcement schedule for four consecutive daily sessions and then a fixed ratio 4 schedule for six consecutive daily sessions. In the continuous reinforcement schedule, each lever press was reinforced with the delivery of a food pellet, and in the fixed ratio 4 schedule every fourth lever press was reinforced by the same reward. Each session lasted $30 \mathrm{~min}$. The rats were thereafter injected intracranially, and $7 \mathrm{~d}$ later the progressive ratio task was started. The rats had to make a criterion number of lever presses to obtain a reward. The criterion was set at two lever presses for the first trial, and then doubled with each successive trial. A test session ended after $2 \mathrm{~h}$ or when the rats had made no response during a 3 min period. The total number of lever presses or rewards was counted during the session.

Statistical analysis. ANOVA, post hoc least significant difference (LSD) test, and Student's $t$ test were used for statistical comparisons with significance set at $p<0.05$. All values were expressed as the mean \pm SEM of the data.

\section{Results}

Generation of $\mathrm{Tg}$ rats for targeting striatopallidal pathway

In our experimental strategy, $\mathrm{Tg}$ animals that express IL-2R $\alpha$ under the control of a cell type-specific promoter are generated. These animals are then treated with a recombinant IT, which consists of anti-IL-2R $\alpha$ monoclonal antibody variable region fused to a bacterial exotoxin fragment, resulting in ablation of target cell types harboring IL-2R $\alpha$ (Kobayashi et al., 1995). To express the human IL-2R $\alpha$ gene in the striatopallidal neurons in rats, we produced a transgene construct, in which the gene cassette containing the human IL-2R $\alpha / \mathrm{mVenus}$ fusion protein (Fukabori et al., 2012) followed by the polyadenylation signal was introduced into exon 2 of the rat Drd2 gene in a BAC clone (Fig.
IT injection eliminates striatopallidal pathway in Tg rats

The DLS and DMS have distinct roles in the acquisition and performance of discrimination tasks associated with sensory stimuli (Brown and Robbins, 1989; Featherstone and McDonald, 2004, 2005). In the present study, we focused on the role of the striatopallidal pathway arising from the DLS in the performance of auditory discrimination. To induce selective elimination of the neural pathway, we injected rats unilaterally with IT solution (8 $\mathrm{ng} / \mathrm{site}$ ) or PBS into the DLS via stereotaxic surgery (Fig. 2 A). Brains were processed $7 \mathrm{~d}$ after the injection, and sections through the striatum were stained with cresyl violet. There was no grossly visible damage seen on the IT- or PBS-injected side in either type of rat (Fig. $2 B$ ). Striatal sections were analyzed by in situ hybridization with a riboprobe covering the $\mathrm{D}_{1} \mathrm{R}$ or $\mathrm{D}_{2} \mathrm{R}$ sequence (Fig. 2C1). A loss of $\mathrm{D}_{2} \mathrm{R}$-containing neurons was visualized on the IT-injected side of the striatum in the Tg rats, and the cell loss was restricted to the DLS, not extending to the DMS and NAc. In contrast, $\mathrm{D}_{1} \mathrm{R}$-containing neurons were preserved in the DLS of the IT-injected Tg rats. The number of DLS neurons containing $\mathrm{D}_{1} \mathrm{R}$ or $\mathrm{D}_{2} \mathrm{R}$ was counted, and the ratio of the number on the IT-injected side to that on the PBS-injected side was calculated (Fig. 2C3). The relative ratio of the number of $\mathrm{D}_{2} \mathrm{R}$-containing neurons was significantly reduced in the Tg rats $(6.9 \%$ of the non-Tg value, $p<0.001$, Student's $t$ test), whereas the ratio of $\mathrm{D}_{1} \mathrm{R}$-containing cell number was indistinguishable between the two types of rats. In addition, we confirmed the distribution of medium spiny neurons by in situ hybridization with a riboprobe covering the preprotachykinin-A (PPTA) or preproenkephalin (PPE) sequence (Fig. 2C2). The number of PPE neurons in the DLS was significantly reduced in the IT-injected $\mathrm{Tg}$ rats $(5.3 \%$ of the non-Tg value, $p<0.001$, Student's $t$ test), whereas that of the PPTA cells was unaltered in 
those animals (Fig. 2C3). Therefore, IT injection induced the selective, efficient elimination of neurons expressing $\mathrm{D}_{2} \mathrm{R}$ and PPE in the Tg rat DLS.

To explore the time course of neuron elimination, rats were injected unilaterally with IT or PBS into their DLS, and striatal sections were prepared on different days after the injection. The sections were stained by in situ hybridization with the $\mathrm{D}_{2} \mathrm{R}$ riboprobe, and the ratio of $\mathrm{D}_{2} \mathrm{R}$-containing neuron number in the DLS on the IT-injected side to that on the PBS-injected side was calculated (Fig. $2 D)$. In the Tg rats, the cell number gradually decreased until day 7 (group effect, $F_{(1,6)}$ $=329.12, p<0.01$; day effect, $F_{(4,24)}=$ $40.85, p<0.01$; group $\times$ day interaction, $F_{(4,24)}=43.28, p<0.01$, ANOVA with repeated measures), and this decreased cell number was sustained on day 9. To further ascertain the elimination of the striatopallidal pathway, we injected BDA solution bilaterally into the DLS for anterograde axonal labeling and then IT or PBS unilaterally into the corresponding area. Synaptic terminals of striatal projections were visualized by BDA staining of sections through the GP or SNr (Fig. $2 E)$. In the Tg rats, striatopallidal synaptic terminals in the GP were considerably diminished on the IT-injected side compared with those on the PBS-injected side, whereas striatonigral synaptic terminals in the $\mathrm{SNr}$ seemed to be intact on both sides. These data support the selective elimination of the striatopallidal pathway in the IT-injected Tg animals.

The dorsal striatum contains cholinergic interneurons and three categories of GABAergic interneurons (Kawaguchi et al., 1995). To investigate the IT response of these interneuronal subtypes, we injected unilaterally IT or PBS into the striatum and performed immunostaining with antibodies against specific markers for each cell type (Fig. 3A1). The number of interneuronal types was counted, and the ratio of the number on the ITinjected side relative to that on the PBS-injected side was evaluated. The number of cholinergic interneurons containing choline acetyltransferase did not differ between the two types of rats (Fig. 3A2), suggesting that the IL-2R $\alpha / \mathrm{mVenus}$ transgene is not expressed in cholinergic interneurons in the Tg rats probably because of the property of the BAC clone used, although these interneurons are known to express $\mathrm{D}_{2} \mathrm{R}$ (Aubry et al., 1993; Alcantara et al., 2003). The number of GABAergic interneurons that express either parvalbumin, somatostatin, or calretinin was also unaffected in the Tg rats (Fig. 3A2).

We checked the influence of the intrastriatal injection of IT on the midbrain dopaminergic neurons. Immunostaining for TH revealed no morphological changes in the cell body of dopaminergic neurons in the SNc and VTA in the IT-injected Tg rats (Fig. 3B1). The number of TH-immunopositive neurons was counted, and the ratio of the number on the IT-injected side relative to that on the PBS-injected side was evaluated. The number of dopaminergic neurons in the SNc or VTA did not alter between the two types of rats (Fig. 3B2). The data are consistent with previous findings showing that the intrastriatal IT injection does not affect the morphology of nigrostriatal dopaminergic neurons expressing IL-2R $\alpha$ in mice (Sano et al., 2003). In addition, immunostaining with antibodies against $\mathrm{TH}$ and vesicular glutamate transporters $1 / 2$ showed no gross morphological changes in dopaminergic and glutamatergic nerve terminals innervating the striatum in the IT-injected Tg animals (Fig. $3 C$ ).

\section{Striatopallidal pathway targeting impairs auditory discrimination performance}

To evaluate how the selective removal of the DLS-derived striatopallidal pathway alters the performance of conditional discrimination, we used a two-choice reaction time task dependent on different auditory stimuli (Robbins et al., 1990). In this task, animals were reinforced to press one of two levers (right or left) depending on two kinds of auditory stimuli (tone $\mathrm{A}$ of $10 \mathrm{kHz}$ or tone $\mathrm{B}$ of $2 \mathrm{kHz}$ ) within a $5 \mathrm{~s}$ test period after the onset of lever presentation. A lever press on the right side in response to tone $\mathrm{A}$ or on the left side in response to tone B within $5 \mathrm{~s}$ was defined as a "correct response," whereas a lever press on the opposite side was defined as an "error response." When the rats did not make a choice within $5 \mathrm{~s}$, the trial was counted as an "omission response." The correct response ratio was taken as the percentage of the number of correct responses divided by the total number of correct and error responses; and the omission ratio, as the percentage of the number of omission responses divided by the total trial number. Rats were trained to reach an average of a correct response ratio of $>80 \%$ in 3 consecutive $\mathrm{d}$. On the next day after achievement of this criterion, the rats were injected with IT or PBS into their DLS; and $7 \mathrm{~d}$ later they were tested for the task performance. The correct response ratio, correct response time, and omission ratio in each session were calculated. The correct response ratio indicated a significant difference among the four groups of rats (Fig. $4 A$; group effect, $F_{(3,45)}=4.16, p<0.05$; 

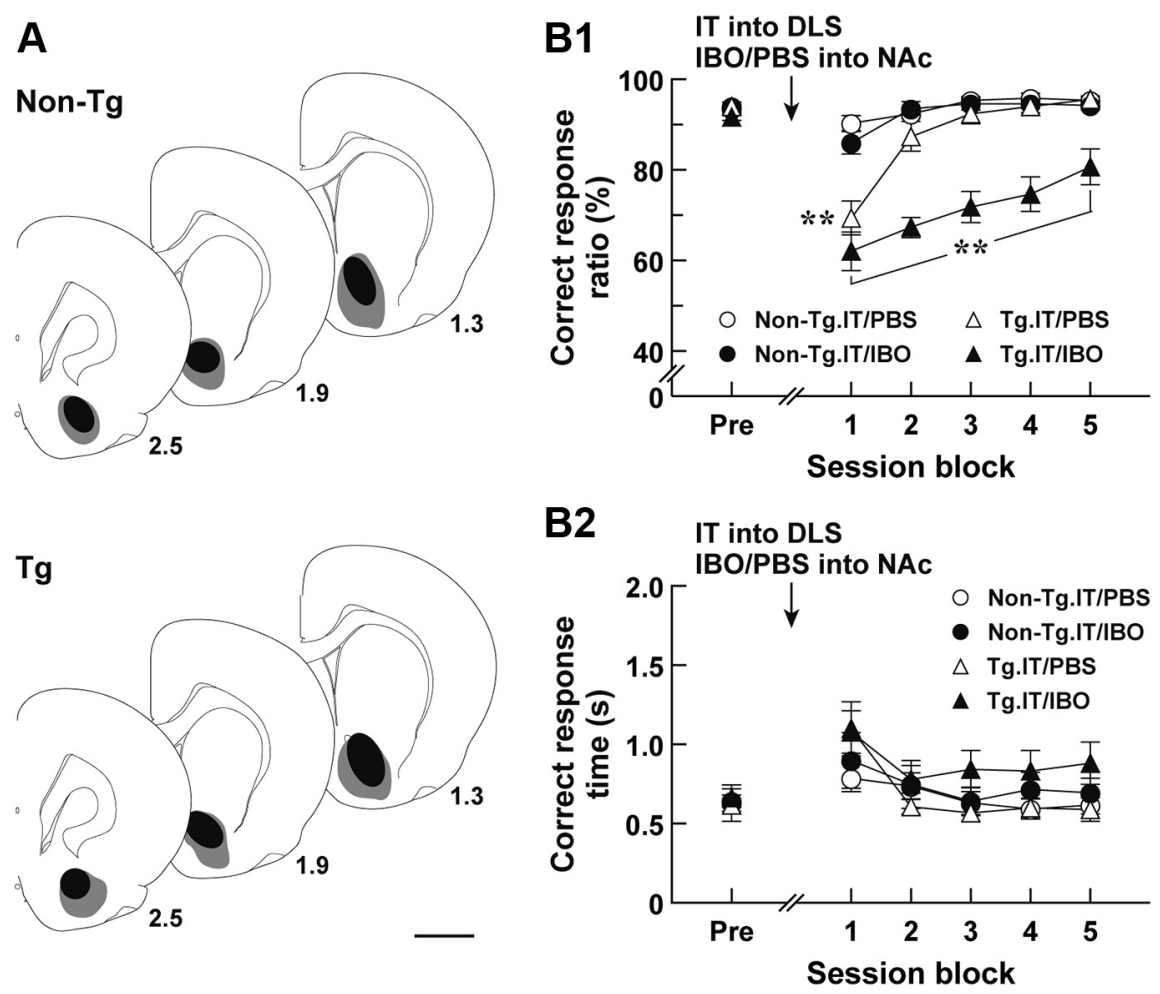

Figure 6. Performance of auditory discrimination in rats with the eliminated DLS striatopallidal pathway and lesioned NAc. Rats ( $n=7-9$ for each group) were trained for the auditory two-choice reaction time task. After achievement of the $80 \%$ criterion, the rats were given a bilateral injection of IT into their DLS and a bilateral injection of IBO or PBS into their NAC, and then tested for the task performance. $\boldsymbol{A}$, Schematic illustration of IBO lesion range in the NAc. After the behavioral test, brains were taken from the $\mathrm{Tg}$ and non-Tg rats; and sections through the NAc were used for NeuN immunohistochemistry. The maximum (gray) and minimum (black) ranges of the lesions are illustrated. The anteroposterior coordinates (millimeters) from the bregma are shown. $\boldsymbol{B}$, Auditory two-choice reaction time task. The correct response ratio $(\boldsymbol{B} 1)$ and correct response time $(\boldsymbol{B} 2)$ in session blocks comprising three serial sessions are plotted. The values at the pretreatment phase (Pre) are the averages at $3 \mathrm{~d}$ before the injection. ${ }^{* *} p<0.05$, compared with each of the IT/PBS- and IT/IBO-injected non-Tg groups, LSD test. Scale bar, $2 \mathrm{~mm}$.

session effect, $F_{(15,675)}=18.85, p<0.01$; group $\times$ session interaction, $F_{(45,675)}=3.64, p<0.01$, ANOVA with repeated measures). The ratio for the IT-injected Tg rats was profoundly reduced at the early phase of test sessions compared with that in the IT- or PBS-injected non-Tg and PBS-injected Tg rat groups ( $p<0.01$ or $p<0.05$, LSD test). Specially, the response ratio on the first session was decreased nearly to the chance level. This reduced response ratio was gradually restored to the control level during the continuing sessions. In contrast, the correct response time and omission ratio were not altered among the four kinds of rat groups (Fig. $4 B, C$ ). Therefore, the elimination of the DLS striatopallidal pathway impaired the accuracy of response selection in the execution of auditory discrimination, although it did not substantially affect the response time or omission ratio.

Overexpression of $\mathrm{D}_{2} \mathrm{R}$ in the striatum in Tg mice disrupts conditional associative learning because of perseveration for responses that were rewarded in a previous trial (Bach et al., 2008). Because the stimulus is randomly presented for each trial, the increased perseveration generates a high frequency of errors when the stimulus changes. To validate perseverative behavior in rats lacking the striatopallidal pathway, we classified all trials in the auditory discrimination task, after a correct response had been made, based on the stimulus repeated or changed in a subsequent trial. We then calculated the error probability, defined as the ratio of the error response number to the correct response number, at the early phase comprising the first three sessions (Fig. 4D). The error probability was significantly higher in the IT-injected Tg rats for the repeated or changed stimulus $\left(F_{(3,45)}=13.19, p<0.01\right.$ for the repeated stimulus; $F_{(3,45)}=5.56, p<$ 0.01 for the changed stimulus, one-way ANOVA). The probability in the changed stimulus tended to increase as compared with that in the repeated stimulus in the corresponding rat groups. These data thus suggest that the disturbed selection accuracy of auditory discrimination was not attributable to the enhanced perseveration for the previously rewarded responses.

\section{Pathway elimination does not impact} locomotion and motivational behavior To examine the consequences of selective ablation of the striatopallidal pathway originating from the DLS in terms of spontaneous locomotion, we injected rats bilaterally with IT or PBS into their DLS, and $7 \mathrm{~d}$ after the injection analyzed them for locomotion in an open field in 10 min sessions during a test period of $60 \mathrm{~min}$. Track length and average velocity of ambulation gradually decreased as the session number increased, showing habituation to the environment, and displayed no difference among the non- $\mathrm{Tg}$ and Tg rats injected with PBS or IT (Fig. $5 A 1, A 2)$. Additionally, we assessed motivation of the rats with a deleted striatopallidal pathway by using a progressive ratio task that measures the amount of effort that an animal continues to obtain a reward. In this paradigm, rats were reinforced to make a set number of lever presses. Two lever presses were needed for the first trial, and the number of lever presses was doubled with each successive trial. The rats were trained sequentially by the continuous reinforcement and fixed ratio 4 schedules, and then injected with IT or PBS into their DLS. After a $7 \mathrm{~d}$ recovery, they started the progressive ratio task. The total number of lever presses or rewards earned during the session was comparable among the four rat groups (Fig. $5 B$ ). Thus, spontaneous locomotion and motivational behavior appeared to be normal in the IT-injected Tg rats, suggesting that the impaired auditory discrimination performance by DLS striatopallidal elimination did not stem from changes in the locomotion and motivational state in these Tg animals.

\section{NAc lesion prevents restoration from learning deficits by striatopallidal removal}

The elimination of the striatopallidal pathway reduced the correct response ratio at the early phase of the auditory discrimination performance, and this reduced performance gradually returned to the normal level as the sessions continued. The NAc is reported to be required for the acquisition of instrumental conditioning (Reading et al., 1991, Kelley et al., 1997). To test whether NAc function is involved in the recovery from the deficits in discrimination performance in rats lacking the striatopallidal pathway, we explored the impact of excitotoxic lesion of the NAc on learning performance of the IT-injected Tg rats. Rats were trained for the auditory two-choice reaction time task; and after achievement of the $80 \%$ criterion they were given bilateral injections of IT into their DLS and of IBO 
solution or PBS into their NAc, and then $7 \mathrm{~d}$ later tested for the task performance (Fig. $6 \mathrm{~A}$ for the range of IBO lesions). The correct response ratio and correct response time in session blocks comprising serial three sessions were evaluated. The correct response ratio revealed a significant difference among the groups of rats (Fig. 6B1; group effect, $F_{(3,28)}=34.39$, $p<0.01$; session block effect, $F_{(5,140)}=$ $38.28, p<0.01$; group $\times$ session block interaction, $F_{(15,140)}=7.92, p<0.01$, ANOVA with repeated measures). The value for the IT/PBS-injected Tg rats was much lower at the first session block compared with that for the IT/PBS-injected or IT/IBO-injected non-Tg control groups $(p<0.05$, LSD test), and then increased at the following session blocks to the control level. In contrast, the correct response ratio for the IT/IBO-injected Tg rats was lower at the first session block, similarly as for the IT/PBS-injected Tg group; but it remained lower even during the subsequent session blocks ( $p<0.05$, LSD test). The correct response time was not significantly different among the four rat groups (Fig. 6B2). Thus, the disruption of the NAc prevented the restoration from discrimination performance deficits in the IT-injected Tg rats, showing the involvement of the NAc in the improved learning performance.

Another possibility that explains the improvement of the learning deficits is that the DMS may participate in the behavioral restoration in the IT-injected Tg rats. Previous studies indicate that the DMS is implicated in the performance, but not in the acquisition, of sensory discrimination (Featherstone and McDonald, 2004, 2005). The DMS also modulates the response time of learned motor actions (Brown and Robbins, 1989). To test whether DMS function contributes to the restoration from the disturbed discrimination performance in rats lacking the striatopallidal pathway, we examined the influence of DMS lesion on the learning performance of the IT-injected Tg rats. After rats had attained the $80 \%$ criterion in the auditory two-choice reaction time task, they were given bilateral injections of IT into their DLS and of IBO or PBS into their DMS, and then tested for the task performance (Fig. 7A, range of IBO lesions). The correct response ratio and correct response time in session blocks comprising continuous three sessions were validated. The correct response ratio showed a significant difference among the four rat groups (group effect, $F_{(3,27)}=7.86, p<0.01$; session block effect, $F_{(5,135)}=122.21, p<0.01$; group $\times$ session block interaction, $F_{(15,135)}=10.34, p<0.01$, ANOVA with repeated measures). The values for the IT/IBO-injected non-Tg and the IT/PBS-injected Tg groups displayed a significant decrease at the first session block compared with that value for the IT/PBS-injected non-Tg control group ( $p<0.01$, LSD test), and they were then restored to the control level. The correct response ratio for the IT/IBOinjected $\mathrm{Tg}$ group was also transiently decreased at the early phase, showing a slight delay of the recovery compared with the ratio for the above two rat groups ( $p<0.01$, LSD test), and finally
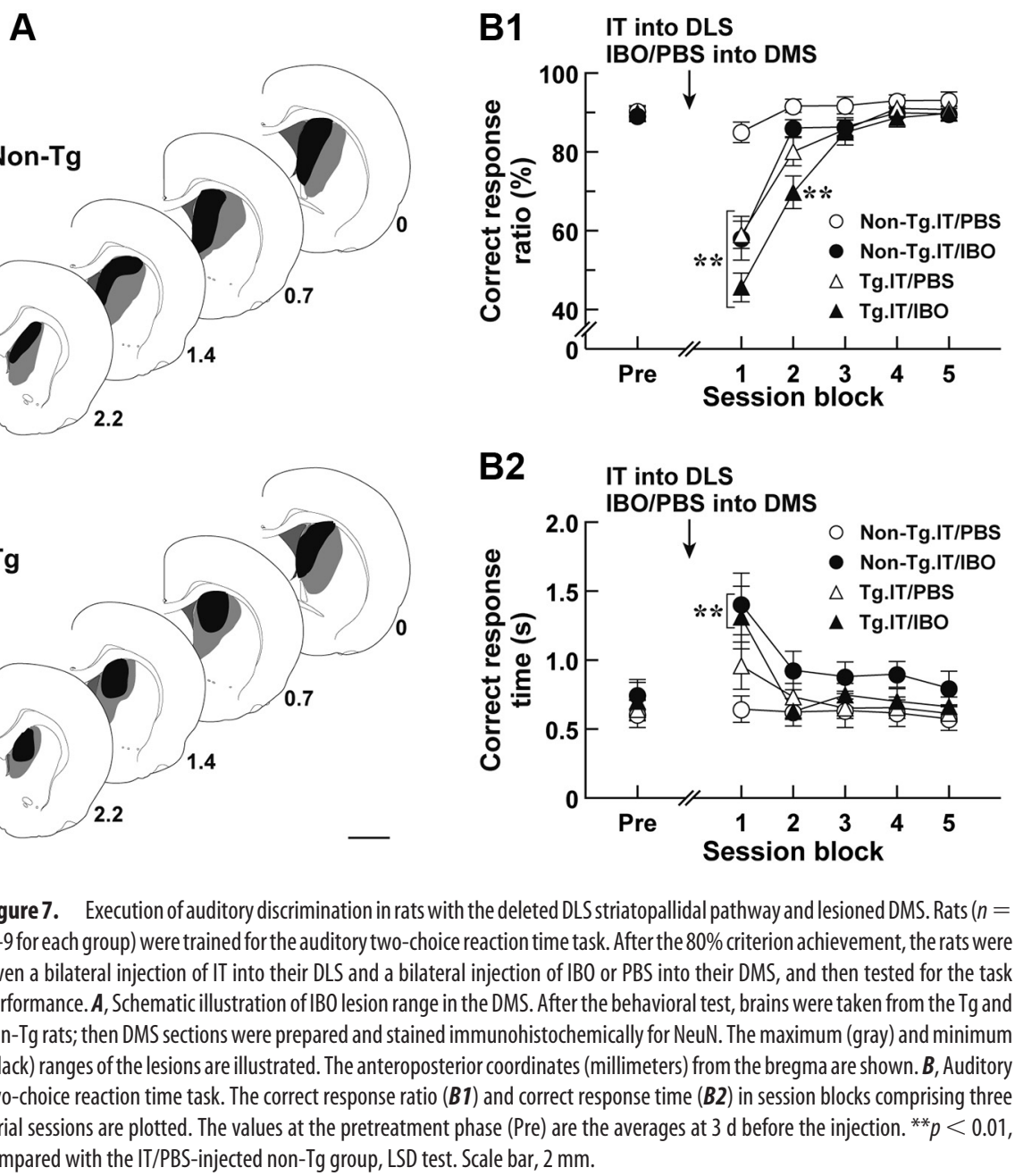

Figure 7. Execution of auditory discrimination in rats with the deleted DLS striatopallidal pathway and lesioned DMS. Rats ( $n=$ 7-9 for each group) were trained for the auditory two-choice reaction time task. After the $80 \%$ criterion achievement, the rats were given a bilateral injection of IT into their DLS and a bilateral injection of IBO or PBS into their DMS, and then tested for the task (black) ranges of the lesions are illustrated. The anteroposterior coordinates (millimeters) from the bregma are shown. $\boldsymbol{B}$, Auditory serial sessions are plotted. The values at the pretreatment phase (Pre) are the averages at $3 \mathrm{~d}$ before the injection. ${ }^{* *} p<0.01$
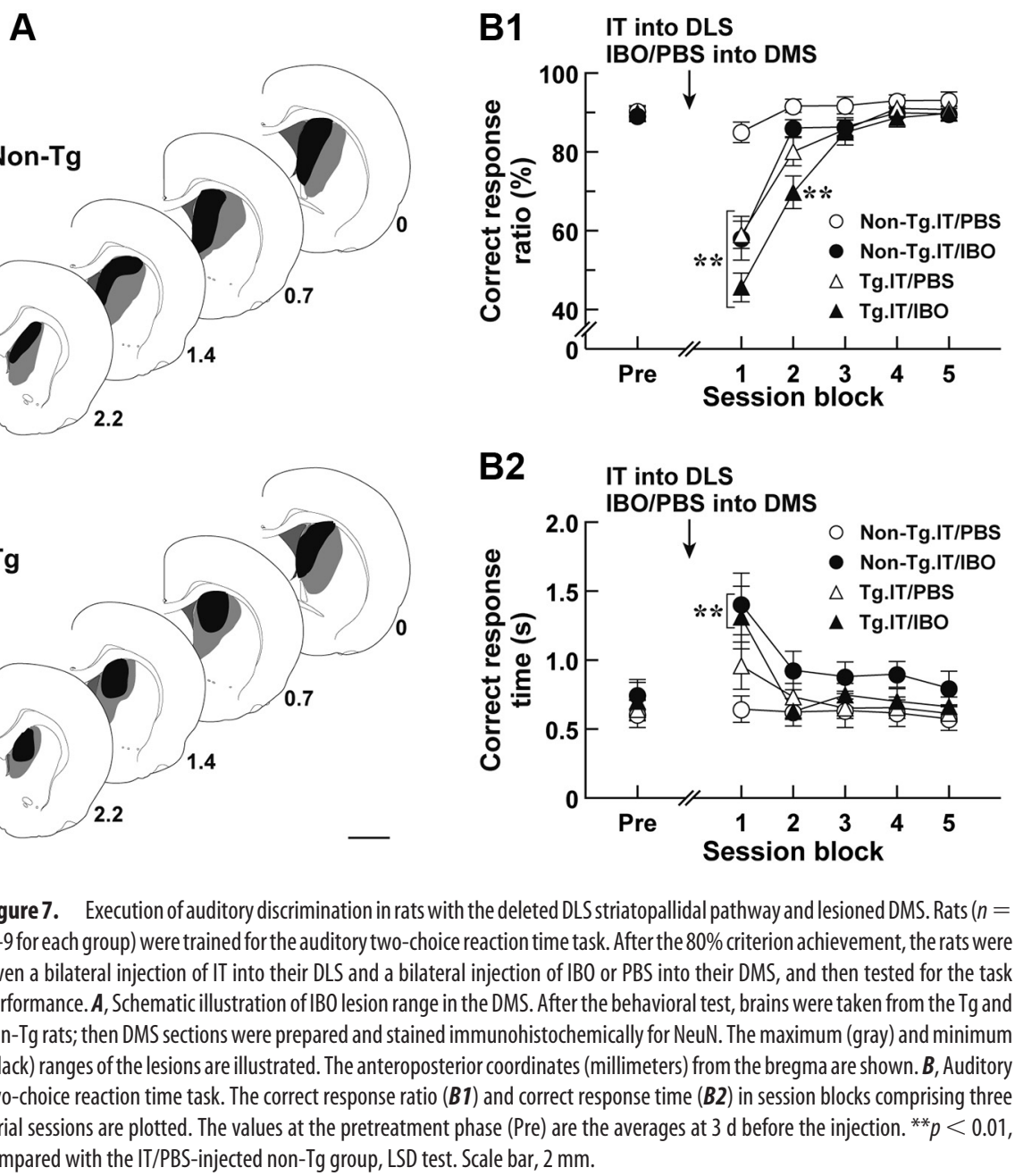

(1)

returned to the control level. The correct response time exhibited a temporal lengthening at the first session block in the IT/IBOinjected non-Tg and Tg groups (Fig. $7 B 2$, group effect, $F_{(3,27)}=$ $2.45, p<0.10$; session block effect, $F_{(5,135)}=12.98, p<0.01$; group $\times$ session block interaction, $F_{(15,135)}=1.79, p<0.05$, ANOVA with repeated measures; $p<0.01$, LSD test) and ameliorated to the normal level at the subsequent session blocks. These data indicate that excitotoxic lesion of the DMS disturbed the accuracy of the response selection in the performance of auditory discrimination in the non- $\mathrm{Tg}$ control rats, supporting the previous view that shows the importance of the DMS in the discrimination performance (Featherstone and McDonald, 2004, 2005). The DMS lesion also resulted in a transient prolongation of correct response time in both non- $\mathrm{Tg}$ and $\mathrm{Tg}$ rats, being consistent with previous data indicating the engagement of the DMS in the response time modulation of learned motor actions (Brown and Robbins, 1989). However, the performance deficits caused by the DMS lesion, combined with DLS striatopallidal elimination, were entirely restored during the repetitive test sessions. The data suggest that DMS function was not necessary for the restoration from the disturbed discrimination performance.

DLS disruption alters auditory discrimination performance A previous study reveals that the DLS is engaged in the executive process of the sensory discrimination task (Featherstone and McDonald, 2005), but the effect of DLS lesion on the response time has not been defined. To ascertain the role of 


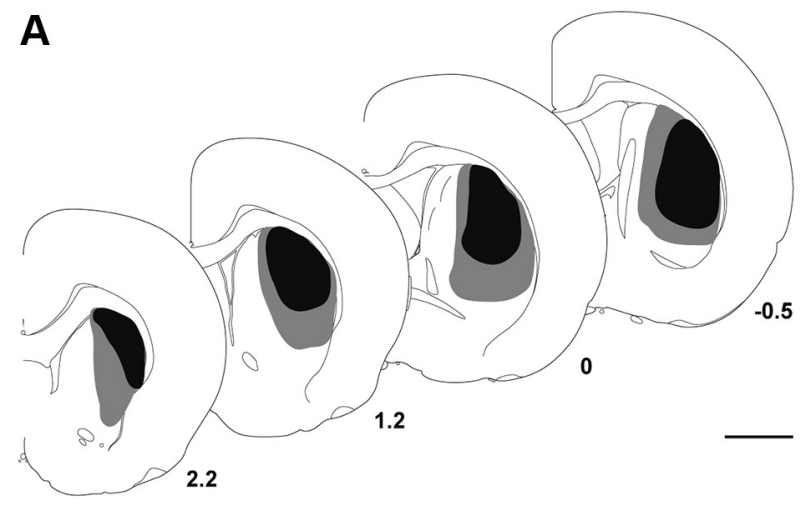

B1

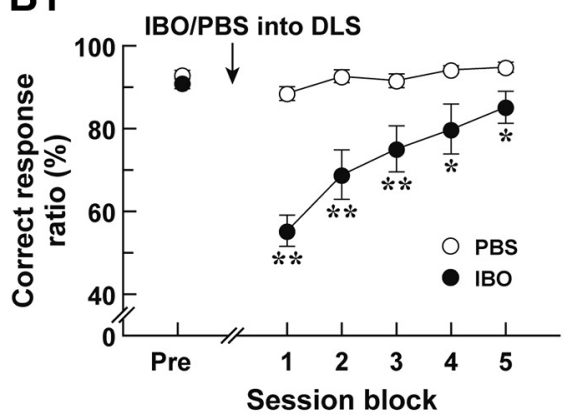

B2

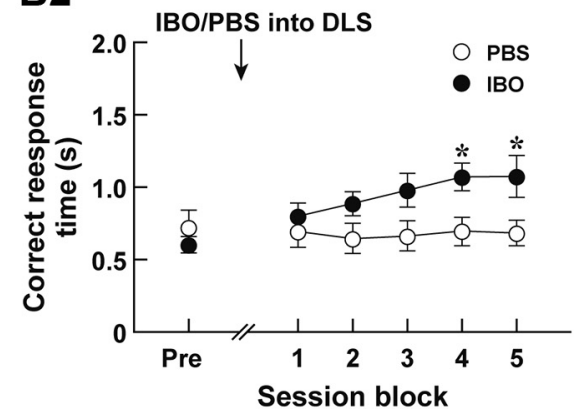

Figure 8. Auditory discrimination performance in animals with DLS disruption. Long-Evans rats ( $n=8$ or 9 for each group) were trained for the auditory discrimination task. After the $80 \%$ criterion achievement, the rats received a bilateral injection of IBO or PBS into their DLS, and then were tested for the task performance. $A$, Schematic illustration of IBO lesion range in the DLS. After the behavioral test, brains were removed from the IBO-treated rats; and DLS sections were prepared and used for immunostaining for NeuN. The maximum (gray) and minimum (black) ranges of the lesions are illustrated. The anteroposterior coordinates (millimeters) from the bregma are shown. $\boldsymbol{B}$, Auditory two-choice reaction time task. The correct response ratio $(\boldsymbol{B} \mathbf{1})$ and correct response time $(\boldsymbol{B} \mathbf{2}$ ) in session blocks comprising three serial sessions are plotted. The values at the pretreatment phase (Pre) are the averages at $3 \mathrm{~d}$ before the injection. ${ }^{* *} p<0.01 ;{ }^{*} p<0.05$, compared with the PBS-injected group, LSD test. Scale bar, $2 \mathrm{~mm}$.

the DLS in the auditory two-choice reaction-time task used in this study, we trained Long-Evans rats to fulfill the $80 \%$ criterion in the task and then injected IBO or PBS into their DLS; and $7 \mathrm{~d}$ later they were tested for the task performance (Fig. $8 \mathrm{~A}$, IBO lesion range). The correct response ratio and correct response time in session blocks comprising three serial sessions were calculated. The response ratio was significantly different between the two groups (Fig. $8 \mathrm{~B} 1$; group effect, $F_{(1,15)}=21.00$, $p<0.01$; session block effect, $F_{(5,75)}=20.49, p<0.01$; group $\times$ session block interaction, $F_{(5,75)}=11.36, p<0.01$, ANOVA with repeated measures). The value for the IBO-treated rat group was declined after the treatment compared with that for the PBStreated rat group, and gradually approached the control value along with the continuation of sessions $(p<0.01$ or 0.05 , LSD test). The correct response time for the IBO-treated group was indistinguishable from that for PBS-treated group at the early stage (session blocks 1-3), but it was lengthened moderately at the later stage (session blocks 4 and 5) (Fig. 8B2; group effect, $F_{(1,15)}=2.77$, not significant; session block effect, $F_{(5,75)}=5.28$, $p<0.01$; group $\times$ session block interaction, $F_{(5,75)}=7.00, p<$ 0.01 , ANOVA with repeated measures; $p<0.05$, LSD test). These data indicate that the DLS was required for the accuracy of response selection in the performance of auditory discrimination and the regulation of correct response time at the late stage of test sessions, which corresponds to the recovery phase from the learning deficits.

Comparison of the aforementioned data with the results obtained from the pathway-specific targeting in the IT-injected Tg rats suggests that the striatopallidal pathway is essential for the role of the DLS in the execution of conditional discrimination. However, this pathway does not appear to mediate the modulation of response time during the recovery of discriminative learning despite the necessity of the DLS for regulation of the response time, suggesting the existence of another neural mechanism that serves for the temporal regulation of motor actions in the process of learning improvement.

\section{Discussion}

We performed selective elimination of the striatopallidal pathway arising from the DLS in Tg rats by using IT-mediated cell targeting. The elimination of this pathway resulted in a marked reduction in the accuracy of response selection but did not influence the response time in auditory conditional discrimination. This impaired response selection was induced at the early phase of test sessions and gradually restored to the normal level as the sessions continued. The restoration from the deficits in discriminative performance was blocked by excitotoxic lesion of the NAc but not by that of the DMS. In addition, lesion of the DLS mimicked the behavioral consequence of the deletion of striatopallidal pathway at the early stage of the auditory discrimination task. These results highlight that the DLS-derived striatopallidal pathway is essential for the execution of conditional discrimination, showing its contribution to the control of selection accuracy of learned motor responses. The results also suggest that the deficits in learned motor selection can be restored during the repetitive sessions, at least in part, depending on accumbal function.

The major finding in the present study is the significance of the DLS-derived striatopallidal pathway in the regulation of the accuracy of response selection in conditional discrimination. Anatomical and electrophysiological studies show that the striatopallidal neurons provide GABAergic inhibition to the GP (Preston et al., 1980; Chang et al., 1981; Nambu and Llinaś, 1994; Oviedo et al., 2008) and that the GP neurons send GABAergic inhibition to the output nuclei and STN (Rouzaire-dubois et al., 1980; Bevan et al., 1997; Sato et al., 2000). The STN neurons exert glutamatergic excitation to the output nuclei and also influence GP activity via axonal collaterals (Robledo and Féger, 1990; Nakanishi et al., 1991). A model of basal ganglia circuitry proposes that the striatopallidal activation causes the increased firing activity of output neurons and thereby suppresses voluntary movement (Mink, 1996; Hikosaka et al., 2000). In addition, reciprocal connections between the GP and STN neurons produce network rhythmicity (Plenz and Kitai, 1999; Bevan et al., 2002). Targeted ablation of the STN cells modulates not only the spontaneous firing rate but also the spiking pattern of the GP and output neurons (Yasoshima et al., 2005). This evidence suggests that the elimination of the DLS striatopallidal pathway in the IT-injected Tg rats alters the rate or pattern of neuronal firing in the basal ganglia nuclei. The 
altered neural activity may interfere with expression of specific motor actions in response to the sensory stimuli, thereby leading to the impaired accuracy of response selection in the performance of discriminative behavior.

Striatal $\mathrm{D}_{2} \mathrm{R}$ overexpression in mice disturbs conditional associative learning due to increased perseveration for the previously rewarded responses (Bach et al., 2008). However, the increased perseveration did not account for the reduced selection accuracy in the auditory discrimination in our IT-injected Tg rats. A previous study with a five-choice reaction time task in rats indicates an elevation in perseverative response by excitotoxic lesion of the DMS but not by that of the DLS (Rogers et al., 2001). Lesion of the DMS in rats or of the medial striatum in marmoset monkeys also impairs reversal learning because of elevated perseverative responses (Clarke et al., 2008; Castañé et al., 2010). These results indicate that perseverative behavior predominantly involves DMS function, being in accord with the observation that the removal of the DLSderived striatopallidal pathway did not generate the increased perseveration in discrimination performance. Again, spontaneous locomotion and motivational behavior, assessed by the progressive ratio task, were apparently normal in the IT-injected Tg rats. Elimination of the striatopallidal neurons from the whole region of the dorsal striatum enhances spontaneous locomotion (Sano et al., 2003). The difference in spontaneous locomotion effects suggests that the pathway elimination from this restricted subregion in the dorsal striatum may not substantially affect locomotor activity. Lesion of the dorsal striatum causes no change in the performance of the progressive ratio task (Eagle et al., 1999), supporting the lack of effect of deleted striatopallidal pathway on motivational behavior.

Excitotoxic lesion of the DLS reduced the accuracy of response selection but did not apparently change the correct response time in the performance of auditory discrimination (at the early phase). The results of a previous study using the five-choice reaction time task indicate that the correct response time of learned motor actions is lengthened by lesion of the DMS but not by that of the DLS (Brown and Robbins, 1989). IT targeting of the striatonigral pathway originating from the DMS elicits a delayed motor response in the execution of visual discrimination (Fukabori et al., 2012). These data imply that the DMS, through the striatonigral pathway, mainly acts to regulate the correct response time in the performance of discriminative behavior. In contrast, the DLS lesion moderately prolonged the motor response at the late stage of test sessions, whereas IT targeting of the striatopallidal pathway from the DLS did not alter the response time of discrimination. Our data demonstrate the engagement of the DLS in response time modulation during the recovery process, and this modulation is independent of the function of the striatopallidal pathway. The temporal regulation of motor response during the learning improvement may be conveyed through the striatonigral pathway derived from the DLS, although the detailed neural mechanism underlying the response time regulation remains to be clarified.

The deficits in learning performance in rats lacking the DLS-derived striatopallidal pathway were restored during the subsequent sessions, at least in part, depending on accumbal function. Because the NAc is involved in the acquisition of instrumental conditioning (Reading et al., 1991; Kelley et al., 1997), our data suggest that the performance deficits in the IT-injected Tg rats may be improved by reacquisition of auditory discrimination. Previous behavioral studies show that excitotoxic lesion of the NAc disrupts Pavlovian conditioning processes, such as appetitive approach behavior (Parkinson et al., 2000; Cardinal et al., 2002b) and conditioned place preference (Everitt et al., 1991). The NAc lesion also impairs Pavlovian influences on the lever pressing (Pavlovian-instrumental transfer), in which presentation of reward-predictive stimuli triggers instrumental responding after both Pavlovian and instrumental trainings (Corbit et al., 2001; Hall et al., 2001). On the contrary, such lesion does not appear to affect the response-reward contingency in goal-directed behavior (Balleine and Killcross, 1994). These data suggest that the NAc mediates the processes of Pavlovian conditioning and Pavlovian-instrumental transfer and contributes to the reacquisition of auditory discrimination to improve the learning deficits caused by the striatopallidal deletion. In addition, excitotoxic lesion of the DLS appeared to delay the recovery from the learning deficits at the late test sessions compared with the selective targeting of the DLS striatopallidal pathway. The data suggest that other types of neurons including striatonigral neurons in the DLS may be partially involved in the recovery process of learning performance. The neural mechanism that explains how other DLS neurons contribute to the learning improvement remains to be addressed in the future.

In conclusion, we found that IT targeting of the striatal indirect pathway arising from the DLS impairs the accuracy of selection of motor responses in conditional discrimination performance. Our previous study indicates that a moderate level of ablation of the striatal direct pathway from the DMS, but not from the DLS, prolongs the correct response time in visual discrimination (Fukabori et al., 2012). Although the role of the DMS-derived indirect pathway in discriminative behavior has not yet been defined, the learning deficits in animals lacking striatofugal pathways may partly represent the cognitive impairments seen in Parkinson's disease and Huntington's disease (Jackson et al., 1995; Brown et al., 2001; Smith and McDowall, 2004). A clearer delineation of the neural circuit mechanism that governs instrumental learning will be useful to elucidate the pathophysiology underlying cognitive symptoms related to neurologic and neurodegenerative diseases.

\section{References}

Alcantara AA, Chen V, Herring BE, Mendenhall JM, Berlanga ML (2003) Localization of dopamine D2 receptors on cholinergic interneurons of the dorsal striatum and nucleus accumbens of the rat. Brain Res 986:22-29. CrossRef Medline

Alexander GE, Crutcher MD (1990) Functional architecture of basal ganglia circuits: neural substrates of parallel processing. Trends Neurosci 13:266271. CrossRef Medline

Aubry JM, Schulz MF, Pagliusi S, Schulz P, Kiss JZ (1993) Coexpression of dopamine $\mathrm{D}_{2}$ and substance $\mathrm{P}$ (neurokinin-1) receptor messenger RNAs by a subpopulation of cholinergic neurons in the rat striatum. Neuroscience 53:417-424. CrossRef Medline

Bach ME, Simpson EH, Kahn L, Marshall JJ, Kandel ER, Kellendonk C (2008) Transient and selective overexpression of D2 receptors in the striatum causes persistent deficits in conditional associative learning. Proc Natl Acad Sci U S A, 105:16027-16032. CrossRef Medline

Balleine B, Killcross S (1994) Effects of ibotenic acid lesions of the nucleus accumbens on instrumental action. Behav Brain Res 65:181-193. CrossRef Medline

Balleine BW, Liljeholm M, Ostlund SB (2009) The integrative function of the basal ganglia in instrumental conditioning. Behav Brain Res 199:43-52. CrossRef Medline

Belin D, Everitt BJ (2008) Cocaine seeking habits depend upon dopaminedependent serial connectivity linking the ventral with the dorsal striatum. Neuron 57:432-441. CrossRef Medline

Bevan MD, Clarke NP, Bolam JP (1997) Synaptic integration of functionally diverse pallidal information in the entopeduncular nucleus and subthalamic nucleus in the rats. J Neurosci 17:308-324. Medline

Bevan MD, Magill PJ, Terman D, Bolam JP, Wilson CJ (2002) Move to the rhythm: oscillations in the subthalamic nucleus-external globus pallidus network. Trends Neurosci 25:525-531. CrossRef Medline 
Brown RG, Redondo-Verge L, Chacon JR, Lucas ML, Channon S (2001) Dissociation between intentional and incidental sequence learning in Huntington's disease. Brain 124:2188-2202. CrossRef Medline

Brown VJ, Robbins TW (1989) Elementary processes of response selection mediated by distinct regions of the striatum. J Neurosci 9:3760-3765. Medline

Cardinal RN, Parkinson JA, Hall J, Everitt BJ (2002a) Emotion and motivation: the role of the amygdala, ventral striatum, and prefrontal cortex. Neurosci Biobehav Rev 26:321-352. CrossRef Medline

Cardinal RN, Parkinson JA, Lachenal G, Halkerston KM, Rudarakanchana N, Hall J, Morrison CH, Howes SR, Robbins TW, Everitt BJ (2002b) Effects of selective excitotoxic lesions of the nucleus accumbens core, anterior cingulate cortex, and central nucleus of the amygdala on autoshaping performance in rats. Behav Neurosci 116:553-567. CrossRef Medline

Castañé A, Theobald DE, Robbins TW (2010) Selective lesions of the dorsomedial striatum impair serial spatial reversal learning in rats. Behav Brain Res 210:74-83. CrossRef Medline

Chang HT, Wilson CJ, Kitai ST (1981) Single neostriatal efferent axons in the globus pallidus: a light and electron microscopic study. Science 213:915-918. CrossRef Medline

Clarke HF, Robbins TW, Roberts AC (2008) Lesions of medial striatum in monkeys produce perseverative impairments during reversal learning similar to those produced by lesions of the orbitofrontal cortex. J Neurosci 28:10972-10982. CrossRef Medline

Corbit LH, Muir JL, Balleine BW (2001) The role of the nucleus accumbens in instrumental conditioning: Evidence of a functional dissociation between accumbens core and shell. J Neurosci 21:3251-3260. Medline

Eagle DM, Humby T, Dunnett SB, Robbins TW (1999) Effects of regional striatal lesions on motor, motivational, and executive aspects of progressive-ratio performance in rats. Behav Neurosci 113:718-731. CrossRef Medline

Everitt BJ, Robbins TW (2005) Neural systems of reinforcement for drug addiction: from actions to habits to compulsion. Nat Neurosci 8:14811489. CrossRef Medline

Everitt BJ, Morris KA, O'Brien A, Robbins TW (1991) The basolateral amygdala-ventral striatal system and conditioned place preference: further evidence of limbic-striatal interactions underlying reward-related processes. Neuroscience 42:1-18. CrossRef Medline

Featherstone RE, McDonald RJ (2004) Dorsal striatum and stimulusresponse learning: lesions of the dorsolateral, but not dorsomedial, striatum impair acquisition of a stimulus-response-based instrumental discrimination task, while sparing conditioned place preference learning. Neuroscience 124:23-31. CrossRef Medline

Featherstone RE, McDonald RJ (2005) Lesions of the dorsolateral or dorsomedial striatum impair performance of a previously acquired simple discrimination task. Neurobiol Learn Mem 84:159-167. CrossRef Medline

Ferguson SM, Eskenazi D, Ishikawa M, Wanat MJ, Phillips PE, Dong Y, Roth BL, Neumaier JF (2011) Transient neuronal inhibition reveals opposing roles of indirect and direct pathways in sensitization. Nat Neurosci 14:22-24. CrossRef Medline

Fukabori R, Okada K, Nishizawa K, Kai N, Kobayashi K, Uchigashima M, Watanabe M, Tsutsui Y, Kobayashi K (2012) Striatal direct pathway modulates response time in execution of visual discrimination. Eur J Neurosci 35:784-797. CrossRef Medline

Gabbott PL, Warner TA, Jays PR, Salway P, Busby SJ (2005) Prefrontal cortex in the rat: Projections to subcortical autonomic, motor, and limbic centers. J Comp Neurol 492:145-177. CrossRef Medline

Gerfen CR, Engber TM, Mahan LC, Susel Z, Chase TN, Monsma FJ Jr, Sibley DR (1990) D1 and D2 dopamine receptor-regulated gene expression of striatonigral and striatopallidal neurons. Science 250:1429-1432. CrossRef Medline

Gerfen CR, Keefe KA, Gauda EB (1995) D1 and D2 dopamine receptor function in the striatum: coactivation of D1- and D2-dopamine receptors on separate populations of neurons results in potentiated immediate early gene response in D1-containing neurons. J Neurosci 15:8167-8176. Medline

Groenewegen HJ, Wright CI, Beijer AV, Voorn P (1999) Convergence and segregation of ventral striatal inputs and outputs. Ann N Y Acad Sci 877: 49-63. CrossRef Medline

Hall J, Parkinson JA, Connor TM, Dickinson A, Everitt BJ (2001) Involvement of the central nucleus of the amygdala and nucleus accunbens core in mediating Pavlovian influences on instrumental behaviour. Eur J Neurosci 13:1984-1992. CrossRef Medline

Hatsuzawa K, Tamura T, Hashimoto H, Hashimoto H, Yokoya S, Miura M, Nagaya H, Wada I (2006) Involvement of syntaxin 18, an endoplasmic reticulum (ER)-localized SNARE protein, in ER-mediated phagocytosis. Mol Biol Cell 17:3964-3977. CrossRef Medline

Hersch SM, Ciliax BJ, Gutekunst CA, Rees HD, Heilman CJ, Yung KK, Bolam JP, Ince E, Yi H, Levey AI (1995) Electron microscopic analysis of D1 and D2 dopamine receptor proteins in the dorsal striatum and their synaptic relationships with motor corticostriatal afferents. J Neurosci 15: 5222-5237. Medline

Hikosaka O, Takikawa Y, Kawagoe R (2000) Role of the basal ganglia in the control of purposive saccadic eye movements. Physiol Rev 80:953-978. Medline

Jackson GM, Jackson SR, Harrison J, Henderson L, Kennard C (1995) Serial reaction time learning and Parkinson's disease: evidence for a procedural learning deficit. Neuropsychologia 33:577-593. CrossRef Medline

Kawaguchi Y, Wilson CJ, Augood SJ, Emson PC (1995) Striatal interneurones: chemical, physiological and morphological characterization. Trends Neurosci 18:527-535. CrossRef Medline

Kelley AE, Smith-Roe SL, Holahan MR (1997) Response-reinforcement learning is dependent on $\mathrm{N}$-methyl-D-aspartate receptor activation in the nucleus accumbens core. Proc Natl Acad Sci U S A 94:12174-12179. CrossRef Medline

Kobayashi K, Morita S, Sawada H, Mizuguchi T, Yamada K, Nagatsu I, Fujita K, Kreitman RJ, Pastan I, Nagatsu T (1995) Immunotoxin-mediated conditional disruption of specific neurons in transgenic mice. Proc Natl Acad Sci U S A 92:1132-1136. CrossRef Medline

Kobayashi K, Okada K, Kai N (2012) Functional circuitry analysis in rodents using neurotoxins/immunotoxins. In: Neuromethods, Vol 65, Controlled genetic manipulations (Alexei M, ed), pp 193-205. New York: Humana.

Kravitz AV, Freeze BS, Parker PR, Kay K, Thwin MT, Deisseroth K, Kreitzer AC (2010) Regulation of parkinsonian motor behavior by optogenetic control of basal ganglia circuitry. Nature 466:622-626. CrossRef Medline

Kreitman RJ, Bailon P, Chaudhary VK, FitzGerald DJ, Pastan I (1994) Recombinant immunotoxins containing anti- $\mathrm{Tac}(\mathrm{Fv})$ and derivatives of Pseudomonas exotoxin produce complete regression in mice of an interleukin-2 receptor-bearing human carcinoma. Blood 83:426-434. Medline

Levey AI, Hersch SM, Rye DB, Sunahara RK, Niznik HB, Kitt CA, Price DL, Maggio R, Brann MR, Ciliax BJ (1993) Localization of $\mathrm{D}_{1}$ and $\mathrm{D}_{2}$ dopamine receptors in brain with subtype-specific antibodies. Proc Natl Acad Sci U S A 90:8861-8865. CrossRef Medline

McGeorge AJ, Faull RL (1989) The organization of the projection from the cerebral cortex to the striatum in the rat. Neuroscience 29:503-537. CrossRef Medline

Mink JW (1996) The basal ganglia: focused selection and inhibition of competing motor program. Prog Neurobiol 50:381-425. CrossRef Medline

Nakanishi H, Kita H, Kitai ST (1991) Intracellular study of rat entopeduncular nucleus neurons in an in vitro slice preparation: response to subthalamic stimulation. Brain Res 549:285-291. CrossRef Medline

Nambu A, Llinaś R (1994) Electrophysiology of globus pallidus neurons in vitro. J Neurophysiol 72:1127-1139. Medline

Narushima M, Uchigashima M, Hashimoto K, Watanabe M, Kano M (2006) Depolarization-induced suppression of inhibition mediated by endocannabinoids at synapses from fast-spiking interneurons to medium spiny neurons in the striatum. Eur J Neurosci 24:2246-2252. CrossRef Medline

Oviedo A, Delgado A, Querejeta E (2008) Differential inhibition of globus pallidus neurons by electrical or chemical stimulation of the striatum. Neurosci Res 62:240-245. CrossRef Medline

Packard MG, Knowlton BJ (2002) Learning and memory functions of the basal ganglia. Annu Rev Neurosci 25:563-593. CrossRef Medline

Parent A, Hazrati LN (1995) Functional anatomy of the basal ganglia. I. The cortico-basal ganglia-thalamo-cortical loop. Brain Res Rev 20:91-127. CrossRef Medline

Parkinson JA, Willoughby PJ, Robbins TW, Everitt BJ (2000) Disconnection of the anterior cingulate cortex and nucleus accumbens core impairs Pavlovian approach behavior: further evidence for limbic cortical-ventral striatopallidal systems. Behav Neurosci 114:42-63. CrossRef Medline

Paxinos G, Watson C (2005) The rat brain in stereotaxic coordinates, Ed 6. Sydney: Academic. 
Plenz D, Kital ST (1999) A basal ganglia pacemaker formed by the subthalamic nucleus and external globus pallidus. Nature 400:677-682. CrossRef Medline

Preston RJ, Bishop GA, Kitai ST (1980) Medium spiny neuron projection from the rat striatum: an intracellular horseradish peroxidase study. Brain Res 183:253-263. CrossRef Medline

Reading PJ, Dunnett SB, Robbins TW (1991) Dissociable roles of the ventral, medial and lateral striatum on the acquisition and performance of a complex visual stimulus-response habit. Behav Brain Res 45:147-161. CrossRef Medline

Robbins TW, Giardini V, Jones GH, Reading P, Sahakian BJ (1990) Effects of dopamine depletion from the caudate-putamen and nucleus accumbens septi on the acquisition and performance of a conditional discrimination task. Behav Brain Res 38:243-261. CrossRef Medline

Robledo P, Féger J (1990) Excitatory influence of rat subthalamic nucleus to substantia nigra pars reticulata and the pallidal complex: electrophysiological data. Brain Res 518:47-54. CrossRef Medline

Rogers RD, Baunez C, Everitt BJ, Robbins TW (2001) Lesions of the medial and lateral striatum in the rat produce differential deficits in attentional performance. Behav Neurosci 115:799-811. CrossRef Medline

Rouzaire-dubois B, Hammond C, Hamon B, Feger J (1980) Pharmacological blockade of the globus pallidus-induced inhibitory response of subthalamic cells in the rat. Brain Res 200:321-329. CrossRef Medline

Sano H, Yasoshima Y, Matsushita N, Kaneko T, Kohno K, Pastan I, Kobayashi
K (2003) Conditional ablation of striatal neuronal types containing dopamine D2 receptor disturbs coordination of basal ganglia function. J Neurosci 23:9078-9088. Medline

Sato F, Lavallée P, Lévesque M, Parent A (2000) Single-axon tracing study of neurons of the external segment of the globus pallidus in primate. J Comp Neurol 417:17-31. CrossRef Medline

Smith JG, McDowall J (2004) Impaired higher order implicit sequence learning on the verbal version of the serial reaction time task in patients with Parkinson's disease. Neuropsychology 18:679-691. CrossRef Medline

Yasoshima Y, Kai N, Yoshida S, Shiosaka S, Koyama Y, Kayama Y, Kobayashi K (2005) Subthalamic neurons coordinate basal ganglia function through differential neural pathways. J Neurosci 25:7743-7753. CrossRef Medline

Yin HH, Knowlton BJ, Balleine BW (2004) Lesions of dorsolateral striatum preserve outcome expectancy but disrupt habit formation in instrumental learning. Eur J Neurosci 19:181-189. CrossRef Medline

Yin HH, Mulcare SP, Hilário MR, Clouse E, Holloway T, Davis MI, Hansson AC, Lovinger DM, Costa RM (2009) Dynamic reorganization of striatal circuits during the acquisition and consolidation of a skill. Nat Neurosci 12:333-341. CrossRef Medline

Yung KK, Bolam JP, Smith AD, Hersch SM, Ciliax BJ, Levey AI (1995) Immunocytochemical localization of $\mathrm{D}_{1}$ and $\mathrm{D}_{2}$ dopamine receptors in the basal ganglia of the rat: light and electron microscopy. Neuroscience 65: 709-730. CrossRef Medline 